\title{
Redesigning Method Engineering Education Through a Trinity of Blended Learning Measures
}

\author{
Sietse Overbeek and Sjaak Brinkkemper \\ Department of Information and Computing Sciences, \\ Faculty of Science, Utrecht University, \\ Princetonplein 5, $3584 \mathrm{CC}$ Utrecht, the Netherlands \\ Email: \{S.J.Overbeek, S.Brinkkemper\}@uu.nl
}

\begin{abstract}
This paper presents a teaching case of a Blended Learning (BL) approach that was applied to a course on Method Engineering (ME) intended for graduate Business Informatics (BIS) students. The main reason for transforming a Master course on ME from traditional to blended is to take advantage of combining frontal instruction with e-learning based instruction and at the same time reducing lecturers' workload in times of increasing student numbers in BIS and Computer Science (CS) areas. The BL approach consists of three parts, as it consists of the introduction of computer-supported peer assessment, interactive e-lectures, and digital examination. The approach has been reflected upon by course lecturers themselves and it was evaluated through two separate student surveys, from which a variety of positive outcomes can be deduced. Increased generation of feedback, an increase in student motivation, and improved understanding of the course content are three of these outcomes that stand out. On top of student related advantages, especially the BL parts concerning peer assessment and digital examination reduce teaching load. These findings are informative for both education researchers and instructors who are interested in embedding BL in BIS or CS education.
\end{abstract}

\section{INTRODUCTION}

Institutions of higher education are increasingly adopting Blended Learning (BL), the combination of face-to-face and technology-mediated instruction [1, p. 185]. In 2011, scholars noted an "explosive growth of blended learning" and acknowledged its potential to become the "new normal" in higher education [2, pp. 207-208]. In 2017 it was indicated that in the foreseeable future a strengthening will be seen of all kinds of digital learning forms, including various kinds of blended learning $[3, p .216]$.

The opportunities that BL has on offer provide possible solutions for dealing with current challenges in Business Informatics (BIS) degrees curricula. Prominent examples of such challenges are the preservation of quality education while experiencing increasing student numbers under tight budgets and to provide students an experience that fits their individual learning styles while reducing restrictions on time and place when offering education [4]. This paper explains a teaching case of how BL has been used to redesign a course on Method Engineering (ME) as part of a Master's degree programme in BIS to deal with the aforementioned challenges. The main research question that has guided the redesign process of this ME course is formulated as follows: "How can we provide Method Engineering students a teaching experience that emphasizes the advantages of blended learning while reducing teaching load at the same time?".

In section II, the course is outlined and the design of the course is explained before the actual application of BL took place. Section III provides an explanation of the BL approach that is used to realize a scalable and technologymediated incarnation of the ME course. Students reflected on the BL approach through two surveys and the results of these reflections are found in section IV. Gathered insights and remaining challenges after reflecting on both the experience of running the $\mathrm{BL}$ version of the ME course and the student evaluations are discussed in section V. Section VI concludes this paper and gives an overview of future research.

\section{BACKGROUND}

The ME course as discussed in this paper is part of a two-year Master's degree programme in BIS. The course is a mandatory course and is offered to students in the first year of the curriculum. Since its inception in 2004, the course has grown from twenty-four to eighty-three participants in 2019. The traditional design of the course consists of regular lectures, lab sessions, and two paper-based exams. During the lab sessions, the students worked individually on their method engineering project. For this project, the students performed a literature review on the topic of a self-selected Information Systems (IS) development method or technique and based on the gathered data from the literature study they designed a meta-model of the selected method or technique. This project was split in five parts and each of the parts was completed by providing a deliverable of which the final deliverable consisted of a term paper that is an integration of the previous deliverables.

The year 2017 was the final year when the ME course ran in a traditional way. With seventy-one participants producing a total of five deliverables and two written exams within a course period of eleven weeks there was substantial pressure on the teaching team to provide feedback on the student materials and grade them. The team consisted of two lecturers and three student assistants (SAs), sometimes also called teaching assistants. The SAs provided guidance during the lab sessions and provided practical support. With eighty-three participants signed up for the 2018 incarnation of the course, the time was ripe to implement proper changes in the design 
of the course in order to deal with increasing student numbers without sacrificing the quality of the course while reducing the teaching load for the entire team. In the following section, the different measures in redesigning the course are further explained.

\section{METHOD ENGINEERING EDUCATION MADE BLENDED AND SCALABLE}

From a birds-eye perspective, the application of BL in the ME course consists of three overall measures, which are: 1) the implementation of computer-supported peer assessment, 2) the introduction of interactive e-lectures, and 3) introducing digital exams. Each of these three overall measures are described in detail in the following sub sections.

\section{A. Computer-supported peer assessment}

The tool 'Revisely' (see: https://revise.ly) is used to cater for online submission of all different deliverables as part of the ME project and, more importantly, it allows for the introduction of peer assessment in the form of peer reviewing and peer grading. By introducing peer assessment, students are able to learn from each other's work. As the students have to work on their own topic for the meta-modelling project, they are able to acquire useful insights when reviewing the modelling choices made by fellow students. Moreover, the students gain experience in providing feedback and grading the work of peers. Finally, through peer assessment a student not only receives feedback from lecturers or student assistants but also from their peers [5, p. 132]. A total of three peer assessment exercises were introduced in the ME project. For the first exercise, students have to peer review and grade a deliverable in which the selected IS development method or technique is explained and positioned relative to existing literature. For the second exercise students have to peer review and grade a deliverable that includes the design of a meta-model of the selected method or technique and for the third exercise students peer reviewed the pre-final term paper without grading it. Based on the feedback acquired from their peer assessors, students write their final term paper that is subsequently assessed and graded by the lecturing team itself. Figure 1 shows a screenshot of the Revisely tool that is used for computer-mediating the peer assessment exercises. Students uploaded their deliverables as PDF documents in the Revisely tool, where a total of three randomly assigned peer assessors needed to provide both textual feedback, i.e., remarks and suggestions for improvement, and scores for the individual grading criteria. These criteria are made available in the Revisely environment and are in fact based on the grading criteria as used by the lecturing team itself in the previous year. To provide the peer assessors with a frame of reference, they are provided with examples from the previous year that were assessed as mediocre / weak, sufficient, and excellent by lecturers. To make sure the peer assessment exercises are conducted in a serious manner, they are required elements for course completion as they are part of the exam rules of the course. This has as a consequence that failure to deliver a serious peer review leads to an inability to pass the course, while the peer assessment results, i.e., the quality of the peer feedback is not graded by the lecturers. For each peer assessment exercise, we found that almost everybody submitted a serious peer assessment. Both the fact that the peer assessments are required elements to pass the course and that three students peer assess each deliverable may further stimulate students to take this task seriously [5, $p$. 103].

After the passing of a peer assessment deadline, the student assistants are asked to inspect the peer assessments, i.e., the feedback and grades given by the peer assessors. In the Revisely tool, every student assistant is assigned an equal share of the deliverables that are indeed commented and graded by three students. A student assistant then checks if the grades that are provided are fair and in line with the quality of a deliverable, if there are outliers in the provided grades, and if the peer review is conducted according to the grading criteria as made available in Revisely. A student assistant also extensifies provided feedback if needed, or adds additional feedback if additions to the peer reviews are needed. As a final step, a student assistant proposes a final grade based on the grades as provided by means of the peer grading activities. When the student assistants are all done performing this 'meta review' of the provided peer reviews, the lecturers conduct a final 'meta meta review', i.e., discussing conspicuities as identified by the student assistants, performing a final check of the meta reviews, and determining the final grade based on the proposals made by the student assistants.

At the end of the day the utilization of this computersupported approach to peer reviewing and peer grading provided at least six clearly identifiable advantages. First and foremost the lecturing team including the student assistants experienced a relieved teaching load as three project deliverables do not need to be reviewed and graded 'from scratch' by lecturers with assistance from student assistants. Secondly, in the past a student would receive feedback on a deliverable from a lecturer and a student assistant. With the peer assessment procedure a student now receives feedback from three fellow students, a student assistant, and possibly a lecturer. Before a lecturer determines the final grade, in fact four suggestions for such a grade are now made by those who have inspected the deliverable. Thirdly, the deliverable submission procedure is streamlined and automated because of the usage of Revisely. Grading criteria are provided online, a randomized match is made between the peer assessees and assessors, student assistants are allocated a fair share of the assessed deliverables and all feedback and grades are made available online for every individual student. Fourthly, the university where this blended Method Engineering course is offered has a support team for lecturers who incorporate BL in their courses, which means that whenever a user of a BL tool that is supported by the university has a tool-related question the support team can step in and there is no need to communicate with the tool supplier itself. Fifthly, through the above approach students are able to experience an increased level of responsibility $[6, p$. 88], i.e., it is their task to not only run a successful ME project 


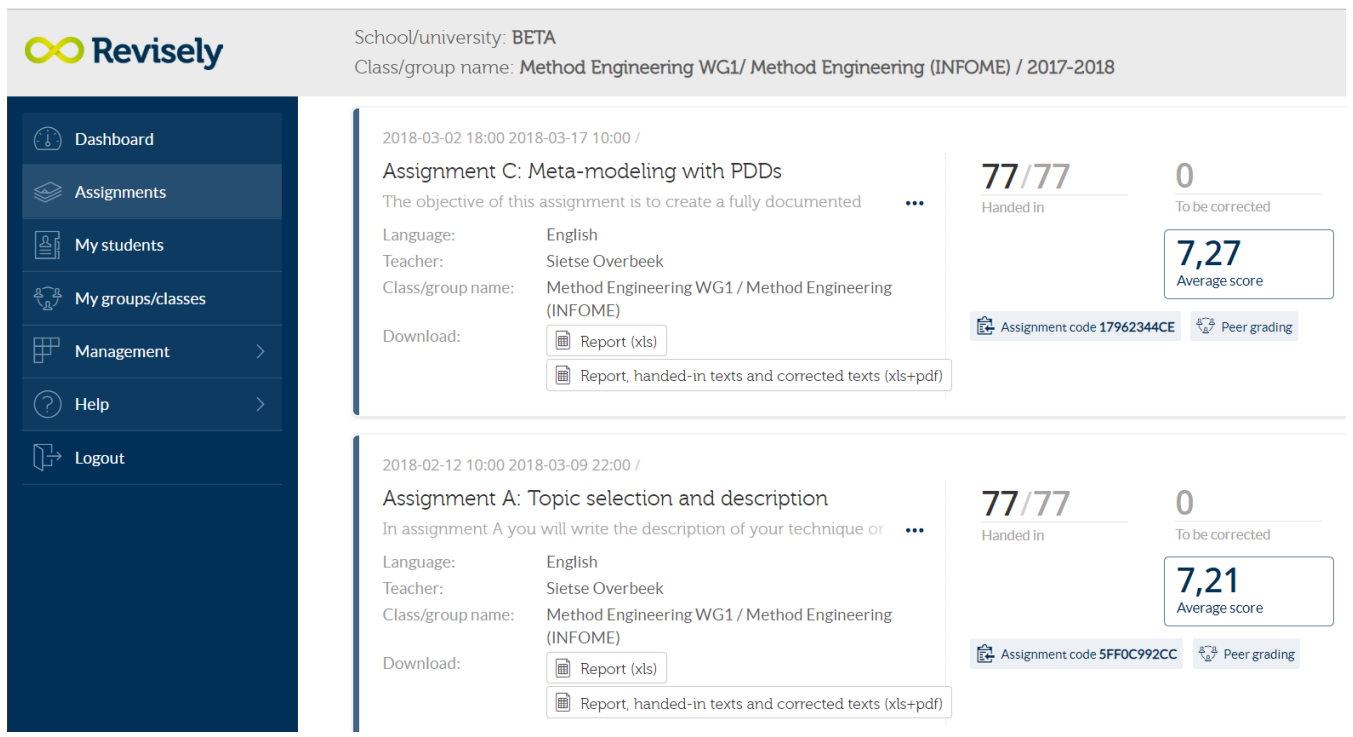

Fig. 1. Screenshot of the Revisely tool

but also to conduct peer assessments in a serious manner. This way, they gain experience in giving feedback to peers and in grading each other's work. Fifthly, lecturers are able to identify those students who come up with high quality reviews, which is a factor in identifying whether they are potential candidates to become the students assistants of the future [7]. Sixthly and finally, introducing peer assessment exercises in addition to the tasks to deliver the ME project deliverables is a way to increase student engagement during the course, which is helpful in times where it is easy for students to spend time on non-study related activities $[5, p$. 132].

\section{B. Interactive e-lectures}

Introduction of interactive e-lectures is the second of the three overall measures taken to apply BL in the ME course as discussed in this paper. A gradual approach is adopted to modify selected regular offline lectures into e-lectures. For the 2018 incarnation of the course, three of the in total eleven regular lectures are transformed into e-lectures. These three lectures are foundational lectures and discuss the topics of meta-data modelling, meta-process modelling, and the role of formalization in ME. Gaining experience in this new teaching mode first before modifying the other regular lectures that discuss advanced ME topics is the key reason for applying such a gradual approach. To modify regular lectures into e-lectures, the tool 'Scalable Learning' (see: www.scalable-learning.com) is used and just as with Revisely this tool has an university-based support team. The e-lectures themselves consist of video material from previously recorded lectures and knowledge clips that were recorded by a student assistant. This student assistant was specifically appointed for this task and recorded short topical clips in a studio on the university campus. These topical clips are in line with what is taught in the three regular lectures. For each e-lecture in the Scalable Learning tool, multiple-choice quiz questions are added to make the e-lectures interactive. The students are asked to prepare each e-lecture, i.e., watch them and make the questions at home or at whatever place they wish. In the lecturer view in Scalable Learning, it is then possible to see who has completed an e-lecture and the answers to the quiz questions can be inspected. The lecturer can then make a selection which questions need to be discussed offline in a classroom setting, for example, those questions that were difficult to answer correctly for the students. Students are also allowed to add their own comments or questions to the video material if there are unclarities while watching the e-lectures. These inaudibilities can also be highlighted for discussion in class. After the students finalized preparation of an e-lecture, an in-class discussion session followed of about an hour each where quiz questions that proved to be difficult and any other unclarities related to the online course material are discussed.

Clear advantages of the approach as described above are threefold. Firstly, students are able to watch the e-lectures anywhere and on their own learning pace, i.e., quickly going over those clips and questions that are easier to grasp for an individual student and more slowly watching material or even repeatedly watching material that is more difficult. Secondly, time is gained as the necessity to be physically present in lecture rooms is reduced. Thirdly, for the overall population of students the lecturer can identify which questions are particularly difficult or more easy to answer and by reviewing the quiz questions the lecturer can shape the offline discussion sessions in order to attune these to the specific audience.

\section{Digital mid-term and final exams}

The third and final measure taken to realize a blended variant of the ME course is the transformation from paperbased exams to digital exams. This measure together with the electronic submission of the ME project deliverables in Revisely has as additional side effect that the ME course is 
now entirely paperless. The university-supported tool Remindo (see: www.paragin.nl) is used to design the digital exams. In previous years, the ME course included two paper-based exams, i.e., a mid-term exam and a final exam. The midterm exam is meant to test knowledge on meta-modelling gained in the first half of the course, while the final exam is for the larger part meant to test knowledge on method engineering theories. The paper-based exams included open questions, while Remindo is ideally suited for administering multiple-choice exams. Introducing multiple-choice questions in both exams provides an opportunity to further reduce the teaching load, as no manual marking is needed for those question types. Transforming open questions where students are asked to design (meta-)models requires to be notably creative, e.g., such an open question can be transformed to a closed variant by dividing the open question in parts where for each closed question a student has to choose the correct modelling alternative from a set of choices [8, $p$. 464]. Another option is to show a partial (meta-)model that a student has to complete by correctly dragging-and-dropping modelling elements such as correctly dragging-and-dropping a metaactivity in the eventual (meta-)model or correctly positioning meta-concepts in the eventual (meta-)model.

The most prominent advantage of this approach is that the time needed for marking is reduced. Instead of grading two times eighty-three exams, Remindo takes most grading work out off the hands as it automatically checks closed questions and is able to deal with negate guessing. Needless to say, digital exams save time and paper as printing of big stacks of exams and carrying these to and from exam rooms becomes a thing of the past. Finally, in case of open questions Remindo removes the possibility of having to deal with unreadable handwriting, as students have to type their answers on notebooks that run Remindo.

\section{STUDENTS' REFLECTIONS ON THE BLENDED LEARNING APPROACH}

The trinity of BL measures as applied in the 2018 incarnation of the discussed ME course has been evaluated by students through: 1) A customary online survey purposefully tailored with specific BL-related open questions that is presented to students at the end of all courses that are part of the Master's degree programme in BIS of which also the mentioned ME course is part of, and 2) through a survey offered by the university's BL support team. The latter survey measures student motivation, differences experienced in learning activities, and experienced learning outputs related to the computer-supported peer assessment part of the trinity [6], [9] and was also offered to students at the end of the course.

Inspired by Unkelos-Shpigel and Hadar [10, p. 189], the survey data has been analyzed in an inductive manner [11], [12] with respect to the part of the main research question that concerns the students' teaching experience by boosting the advantages of blended learning. The customary online survey shows insights on experiences of all three BL measures and it was filled out by thirty-eight of the eighty-three participants in
2018. The following responses on peer assessment are found and they happen to be rather self-explanatory:

"I like Revisely and did not have any issues with it. Grading others' work gives better insight into your own work"

"I would keep the assignment format and Revisely. It is nice how each assignment builds into the final paper. It was really stress-free and I enjoyed it"

"Revisely provides an OK platform for submissions and peer reviews"

The responses related to the interactive e-lectures show that students perceived an added value in the activating effect these kind of lectures have and in the 'blended' aspect of having online and offline lectures. The apparent usefulness of the electures is also emphasized:

"The e-lectures [...] demanded active participation [by means of answering] the [quiz] questions"

"Enjoyed the different elements in the course, [I] like the combination of the regular lectures with the e-lectures"

"e-Lectures are a great addition in my opinion"

"The e-lectures should [remain for next year, they were] very useful"

The following responses concern the third and final BL measure which is the introduction of digital exams:
"I found the flipped classroom [and] digital exams [...] very helpful"
"The mid-term exam was good. I'm a big fan of the digital exam and it was carefully constructed as to test the knowledge of [meta-modelling] despite the [common view] that open exams would be a better way to [test this kind of knowledge]"
"While I'm not a fan of multiple choice questions, I'm glad the majority of the questions were about understanding the content as opposed to [sheer memorizing of] it"

One response concerned a positive impression of the course as a whole:
"Compared to last year the course has really im- proved"

This impression resonates when comparing last year's average grade given for the course by students in 2017 with this year's average grade, as the respondents in 2018 evaluated the overall quality of this course to be a 7.5 on a scale of 1 to $10(\mathrm{~N}=32$ with a standard deviation of 1$)$, whereas last year this score was a $6.5(\mathrm{~N}=26$, standard deviation of 1.5$)$.

The survey offered by the university's BL support team was filled out by a total of seventy-one out of the eightythree course participants in 2018. The ME students provided their answers on a five-point Likert scale, where ' 1 ' means 'completely disagree' and ' 5 ' means 'completely agree'. In table I the averages are shown for the ME course and for two other courses that also used Revisely for computersupported peer assessment with a total of one hundred and 
fourteen respondents. In the rightmost column the averages are shown for all courses within the university that are using university-supported BL tooling since 2016. In that year the university's BL support team was formed and since then surveys are offered to those lecturers who use universitysupported BL tools. The table shows that students indicated to have received more feedback and also gave more feedback by using computer-supported peer assessment in the ME course. This is an indication that the main aim of the peer assessment approach is largely met, which is to offer an environment to provide peer feedback and peer grading. On average, students were also highly positive about the way the peer assessment approach affected their motivation and that they were able to learn more and understand the course content better. The students were less positive about 1) the joy experienced while using computer-supported peer assessment, 2) the effect it had on their ability to pass the exams, and 3) the extent to which it helped them to understand the lectures better. In the future, it will be investigated how to improve on these three less positive aspects.

\section{Discussion}

After analyzing the results of the student surveys in full, there are other observations that are deemed relevant for further discussion apart from the three more critical aspects as mentioned at the end of section IV. After discussing these observations, some interesting points that are specifically related to the peer assessment part are mentioned at the end of this section.

Meta-review to overcome peer reviews of varying quality Concerning the peer assessments, respondents indicated that the quality of peer reviews may differ and grades given for peer graded deliverables are not always in line with each other. These effects were anticipated on in the design of the blended variant of the ME course by introducing three peer reviewers [13, p. 43] and by conducting a round of meta- and meta meta reviewing as discussed in section III-A. However, it does not prevent students from experiencing differences in quality and differences in grades given to their work as the results of a peer assessment are visible in the Revisely tool once a peer assessment is finalized by a fellow student. Although the final grade for their work is given by a lecturer, a respondent wondered what effect an outlier had on the final grade as this was not consistently articulated in the final feedback. Apart from an obvious solution to make explicit in the final feedback of the meta-meta-review what has been done with a possible outlier when determining a final grade, the introduction of an entire instructional lecture dedicated to peer assessment would be a plausible idea, instead of maintaining the current practice of instructing students in an ad hoc manner how to conduct a peer assessment as part of a topical lecture and during workshops where they work on their practical exercises [9, p. 103].

\section{Student opinions in two camps}

In the responses concerning the interactive e-lectures it was found not every student liked the idea of having to watch the e-lectures and prepare the accompanying quiz questions. Some students feel a lack of opportunity to interact with others, i.e., lecturer and fellow classmates in a live classroom setting. However, the Scalable Learning tool offers the possibility for lecturers to comment on questions that are raised by students while preparing the e-lectures and to at least asynchronously interact with students before the actual in-class discussion session takes place. What will be done for the next iteration of the course is to explicitly emphasize in class the possibilities to asynchronously communicate with lecturers by making use of the option to raise questions and clearly indicate where unclarities are. Watching interactive e-lectures remains a different form of education when compared to a traditional lecture, however, and it depends on an individual's learning preferences how this modern educational form is experienced. Another notable aspect which is in fact sensible advice is that students indicate the e-lectures should always include knowledge clips that are of identical quality when compared to regular lectures and that lecturers should prevent knowledge clips from becoming second-rate replacements of regular lectures.

\section{Multiple-choice exams with an option to comment}

From the responses to the customary online survey it becomes clear that among students who are unfamiliar with multiple-choice exams or who have a preference for open question exams there is a desire to provide comments in the digital exam environment next to only being able to select the proper answers. Multiplechoice exams with an option to comment provides students with an opportunity to write down their thought-line that led to the selection of an answer. Nield and Wintre [14] indicated that this approach reduces frustration and produces less anxiety among students. How to implement this in the digital exam environment is a different matter, i.e., it is not a standard option to choose from in the Remindo tool and as such how to deal with this challenge is part of future research.

\section{Overcoming glitches in technology-mediated peer assess- ment}

Concerning the technology-mediated peer assessment part there are some noteworthy experiences from the point of view of the ME course lecturers. As mentioned before, after the submission deadline of a deliverable that was going to be peer reviewed in Revisely had passed, three reviewers were assigned to each submission. It was found that the tool supported random assignment of one reviewer only, meaning the assignment of three reviewers had to be done manually which is a more time consuming and error-prone process. The tool also 
TABLE I

COMPUTER-SUPPORTED PEER ASSESSMENT EVALUATION RESULTS

\begin{tabular}{|c|c|c|c|}
\hline $\begin{array}{l}\text { By using the computer-supported } \\
\text { peer assessment approach I ... : }\end{array}$ & $\begin{array}{l}\text { ME course } \\
\quad N=71\end{array}$ & $\begin{array}{l}\text { Other courses } \\
\quad N=114\end{array}$ & $\begin{array}{c}\text { Totals for BL courses } \\
\qquad N=3135\end{array}$ \\
\hline $\begin{array}{l}\text { Motivation } \\
\text { was motivated } \\
\text { experienced joy } \\
\text { had the impression it was useful } \\
\text { had the impression it supported me } \\
\text { in passing the exams }\end{array}$ & $\begin{array}{l}3.69 \\
2.69 \\
4.03 \\
2.92\end{array}$ & $\begin{array}{l}3.49 \\
2.91 \\
3.86 \\
\\
2.99\end{array}$ & $\begin{array}{l}3.46 \\
3.33 \\
3.73 \\
\\
3.19\end{array}$ \\
\hline $\begin{array}{l}\text { Learning activities } \\
\text { was more active with the content } \\
\text { was able to better study the content } \\
\text { was able to improve collaboration } \\
\text { received more feedback } \\
\text { gave more feedback }\end{array}$ & $\begin{array}{l}3.33 \\
3.32 \\
3.00 \\
4.37 \\
4.28\end{array}$ & $\begin{array}{l}3.02 \\
2.95 \\
2.91 \\
4.27 \\
3.70\end{array}$ & $\begin{array}{l}3.47 \\
3.17 \\
2.72 \\
3.32 \\
3.13\end{array}$ \\
\hline $\begin{array}{l}\text { Experienced learning outputs } \\
\text { learned more in this course } \\
\text { understood the content better } \\
\text { was better prepared for the exams } \\
\text { was better prepared for the lectures } \\
\text { understood the lectures better }\end{array}$ & $\begin{array}{l}3.54 \\
3.44 \\
2.79 \\
2.97 \\
2.69\end{array}$ & $\begin{array}{l}3.28 \\
3.17 \\
2.74 \\
2.85 \\
2.53\end{array}$ & $\begin{array}{l}3.32 \\
3.30 \\
3.16 \\
2.84 \\
3.01\end{array}$ \\
\hline
\end{tabular}

has the functionality that if students finalize their peer review, the reviewee can immediately see the feedback. This has as an advantage that feedback is seen much quicker when compared to an instructor review approach. However, it was found that once a peer reviewer marks the review as finalized, there is no option to undo. It happened a couple of times that a peer reviewer would mark a review as finalized accidentally. As a workaround additional feedback could then be exchanged between the reviewer and reviewee by e-mail. Finally, a pressing issue was that three students were not allowed to review the same deliverable at the same time. If they did, added feedback could be lost. As a workaround students were asked to store their review on a local drive first and then they were asked to always communicate with the other peer reviewers of the deliverable in case one of the three reviewers would start performing a review. The above experiences were all communicated to the university's BL support team who maintained close ties with the tool supplier and as such formed improvement points for the next release of the tool.

\section{CONCLUSIONS AND FUTURE RESEARCH}

In this paper a redesign approach was presented for transforming a Master's course on Method Engineering as part of an BIS curriculum into a blended variant. A trinity of blended learning measures have been proposed, that were driven by the desire to realize 1) a course design that preserves quality education in a time where student numbers in CS and BIS curricula are increasing while university budgets remain tight, and 2) to offer a teaching experience that fits with individual learning styles while reducing time and place restrictions. The three measures included the introduction of technologymediated peer assessment, interactive e-lectures, and digital examination. Most prominent advantages of the peer assess- ment measure are the reduction of teaching load, increased generation of feedback itself, increased student experience in providing feedback, and increased student motivation and engagement. The introduction of interactive e-lectures enabled students to watch the e-lectures anywhere, anytime, and on their own learning pace. There is a time gain as e-lectures replace regular lectures, however, quiz results need to be reviewed by lecturers and then in-class discussion sessions need to be organized. This offers the advantage of tailoring these sessions in such way that the difficult questions as part of the e-lectures receive most attention. Clear benefits of digital examination include reduced marking time and elimination of paper-based exams.

For next year, the blended approach will be maintained in the Method Engineering course and improvements will be implemented, based on opportunities identified in the student survey results and by means of reflecting on the course from a lecturer's point of view. An instructional lecture purely dedicated to peer assessment will be introduced, possibilities to stimulate student-student and student-lecturer interaction will be explored when students are watching e-lectures, electure quality will be double-checked and where needed further improved, and it will be investigated whether multiplechoice exams with an option to comment can be realized. Finally, based on the peer assessment survey results it will be investigated how students are able to experience more joy while using computer-supported peer assessment (and BL tools in general for that matter), in what ways peer assessment can make an impact on the ability to pass exams, and it will be inventorized how it helps students to increase understanding of the course content.

\section{REFERENCES}

[1] W. W. Porter, C. R. Graham, K. A. Spring, and K. R. Welch, "Blended learning in higher education: Institutional adoption and implementation," 
Computers \& Education, vol. 75, pp. 185-195, 2014, doi: 10.1016/j. compedu.2014.02.011.

[2] A. Norberg, C. D. Dziuban, and P. D. Moskal, "A timebased blended learning model," On the Horizon, vol. 19, no. 3, pp. 207-216, 2011, doi: 10.1108/10748121111163913.

[3] B. van der Zwaan, Higher Education in 2040: A Global Approach. Amsterdam, the Netherlands: Amsterdam University Press, 2017.

[4] D. Garrison and H. Kanuka, "Blended learning: Uncovering its transformative potential in higher education," The Internet and Higher Education, vol. 7, no. 2, pp. 95-105, 2004, doi: 10.1016/j.iheduc.2004.02.001.

[5] B. Jones, Motivating Students by Design: Practical Strategies for Professors. Blacksburg, USA: Brett D. Jones, 2018.

[6] R. M. Filius, R. A. de Kleijn, S. G. Uijl, F. J. Prins, H. V. Rijen, and D. E. Grobbee, "Strengthening dialogic peer feedback aiming for deep learning in SPOCs," Computers \& Education, vol. 125, pp. 86-100, 2018, doi: 10.1016/j.compedu.2018.06.004.

[7] D. G. Collings, H. Scullion, and P. M. Caligiuri, Eds., Global Talent Management, 2nd ed. New York, USA: Routledge, 2019.

[8] A. De Lucia, C. Gravino, R. Oliveto, and G. Tortora, "An experimental comparison of ER and UML class diagrams for data modelling," Empirical Software Engineering, vol. 15, no. 5, pp. 455-492, 2010, doi: 10.1007/s10664-009-9127-7.

[9] R. M. Filius, R. A. de Kleijn, S. G. Uijl, F. J. Prins, H. V. Rijen, and D. E. Grobbee, "Promoting deep learning through online feedback in SPOCs," Frontline Learning Research, vol. 6, no. 2, pp. 92-113, 2018, doi: 10.14786/flr.v6i2.350.

[10] N. Unkelos-Shpigel and I. Hadar, "Test first, code later: Educating for test driven development," in Advanced Information Systems Engineering Workshops, R. Matulevičius and R. Dijkman, Eds. Cham, Switzerland: Springer International Publishing, 2018, pp. 186-192, doi: 10.1007/978-3-319-92898-2_16.

[11] B. Oates, Researching Information Systems and Computing. Thousand Oaks, USA: SAGE Publications, 2006.

[12] A. Strauss and J. Corbin, Basics of Qualitative Research: Techniques and Procedures for Developing Grounded Theory. Thousand Oaks, USA: SAGE Publications, 1998.

[13] S. P. Balfour, "Assessing writing in MOOCs: Automated essay scoring and calibrated peer review," Research \& Practice in Assessment, vol. 8, pp. 40-48, 2013

[14] A. F. Nield and M. G. Wintre, "Multiple-choice questions with an option to comment: Student attitudes and use," Teaching of Psychology, vol. 13, no. 4, pp. 196-199, 1986, doi: 10.1207/s15328023top1304_6. 